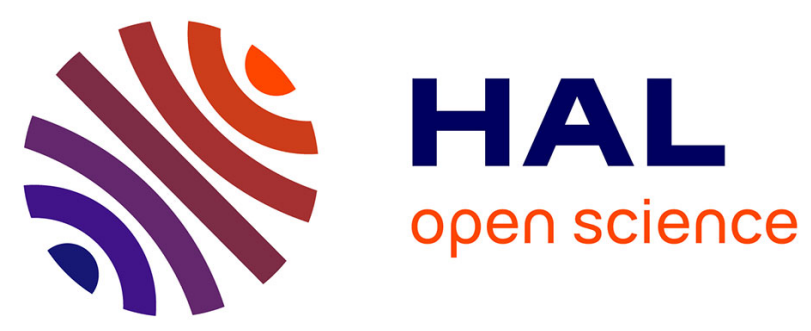

\title{
Polar stratospheric cloud observations over the Antarctic continent at Dumont d'Urville
}

Leopoldo Stefanutti, Marco Morandi, Massimo del Guasta, Sophie Godin, Gérard Mégie, Jacques Brechet, Jacques Piquard

\section{To cite this version:}

Leopoldo Stefanutti, Marco Morandi, Massimo del Guasta, Sophie Godin, Gérard Mégie, et al.. Polar stratospheric cloud observations over the Antarctic continent at Dumont d'Urville. Journal of Geophysical Research: Atmospheres, 1991, 96 (D7), pp.12975-12987. 10.1029/91JD00776 . insu03052658

\section{HAL Id: insu-03052658 \\ https://hal-insu.archives-ouvertes.fr/insu-03052658}

Submitted on 2 Feb 2021

HAL is a multi-disciplinary open access archive for the deposit and dissemination of scientific research documents, whether they are published or not. The documents may come from teaching and research institutions in France or abroad, or from public or private research centers.
L'archive ouverte pluridisciplinaire HAL, est destinée au dépôt et à la diffusion de documents scientifiques de niveau recherche, publiés ou non, émanant des établissements d'enseignement et de recherche français ou étrangers, des laboratoires publics ou privés. 
POLAR STRATOSPHERIC CLOUD OBSERVATIONS OVER THE ANTARCTIC CONTINENT AT DUYONT D'URVILLE

L. Stefanutti, M. Morandi, and M. De1 Guasta

Istituto di Ricerca sulle Onde Electromagnetiche Consiglio Nazionale della Ricerche, Firenze, Italy

\section{S. Godin and G. Megie}

Service d'Aéronomie du Centre National de la Recherche Scientifique, Université Pierre et Marie Curie, Paris, France

\section{J. Brechet and J. Piquard}

Expeditions Polaires Francaises, Paris, France

Abstract. The Istituto di Ricerca sulle Onde Electromagnetiche (IROE) two-channel elastic backscattering lidar [Sacco et al., 1989], suitable for depolarization measurements, has been operated since January 8 , 1989, at the French Antarctic base of Dumont d'Urville $\left(66^{\circ} 40^{\prime} \mathrm{S}, 140^{\circ} \mathrm{O} 1^{\prime} \mathrm{E}\right)$. A continuous monitoring of the stratosphere was performed, which permitted measurement of the evolution of the background stratospheric aerosols and of polar stratospheric clouds (PSC) throughout the year. The data reported in this article correspond to the first year of measurements. Depolarization of the lidar signals was measured in order to obtain information on the type of clouds observed and on their particle size distribution. Both low $(<10 \%)$ and high (>10z) depolarization ratios were detected, permitting discrimination between types $\mathrm{Ia}, \mathrm{Ib}$, and II PSC according to the classification given by Toon et al. (1990). Temporal continuity and high time resolution of the lidar measurements are evidence for altitude decreases in the PSC layers over periods of a few hours. These motions, if linked to sedimentation processes, led to values of velocity $\left(\approx 10 \mathrm{~cm} \mathrm{~s}^{-1}\right.$ ) compatible with large particles.

\section{Polar Ozone Lidar Experiment (POLE)}

The POLE Experiment is organized under an Italian-French cooperation program for Antarctic research, in the frame of the Italian National Program for Antarctic Research (PNRA) and the Territoires des Terres Australes et Antarctiques Françaises (TAAF). The first step of this program is the implementation at Dumont d'Urville of an elastic backscattering lidar designed for both tropospheric cloud and statospheric aerosol measurements. The system, which has been previously described [Sacco et al., 1989] operates at $0.53 \mu \mathrm{m}$, with a linearly polarized laser pulse and a repetition rate of $4 \mathrm{~Hz}$. Signals on both the parallel and perpendicularly polarized planes relative to the emitted laser

Copyright 1991 by the American Geophysical Union.

Paper number 91JD00776.

$0148-0227 / 91 / 91 J D-00776 \$ 05.00$ radiation are collected. Thus the depolarization induced by nonspherical particles, such as ice crystals, may be measured.

Analog detection of the time-resolved signal is performed by means of a 12-bit, 5-MHz transient digitizer. Stratospheric lidar profiles are stored in a suitable way on an 0livetti M 380 computer and then transmitted by means of electronic link via IMMARSAT to the BITNET knot of Singapore, and further transmitted to Instituto di Ricerca sulle Onde Electromagnetiche in Italy and to the Service d'Aéronomie in France.

The system was first tested at the Italian base of Terra Nova Bay $\left(74^{\circ} 41^{\prime} 42^{\prime \prime} \mathrm{S}, 164^{\circ} 07^{\prime} 23^{\prime \prime} \mathrm{E}\right)$ during the summer of 1987-1988 [Sacco et al., 1989]. It was then transported to Dumont d'Urville in December 1988 and started operation in January 1989.

\section{Methodology}

\section{Backscattering Coefficient and Scattering Ratio}

For each channel, the scattering ratio is defined as

$$
R_{i}=\frac{\beta_{m i}+\beta_{o i}}{\beta_{m i}}
$$

where $\beta_{m i}$ and $\beta_{a j}$ are the Rayleigh and Mie backscattering coefficient in the 1 -polarization plane, respectively. Channel 1 corresponds to the p-polarization plane and channel 2 to the $s$ polarization plane.

Figure 1 shows a typical lidar profile of backscattering coefficient and scattering ratio for the p-polarization plane. The reference molecular atmosphere represented in this figure is obtained by averaging all radiosoundings temperature and pressure data obtained in January 1988, for heights up to $25 \mathrm{~km}$ and using an exponential approximation above.

The backscattering ratio is calculated by normalizing the lidar signature to the molecular atmosphere at heights between 28 and $32 \mathrm{~km}$. It is then corrected for aerosol extinction between 10 and $25 \mathrm{~km}$, using an average backscatter to extinction ratio value of 0.05 in the presence of PSC and/or cirrus clouds, as revealed by strong 

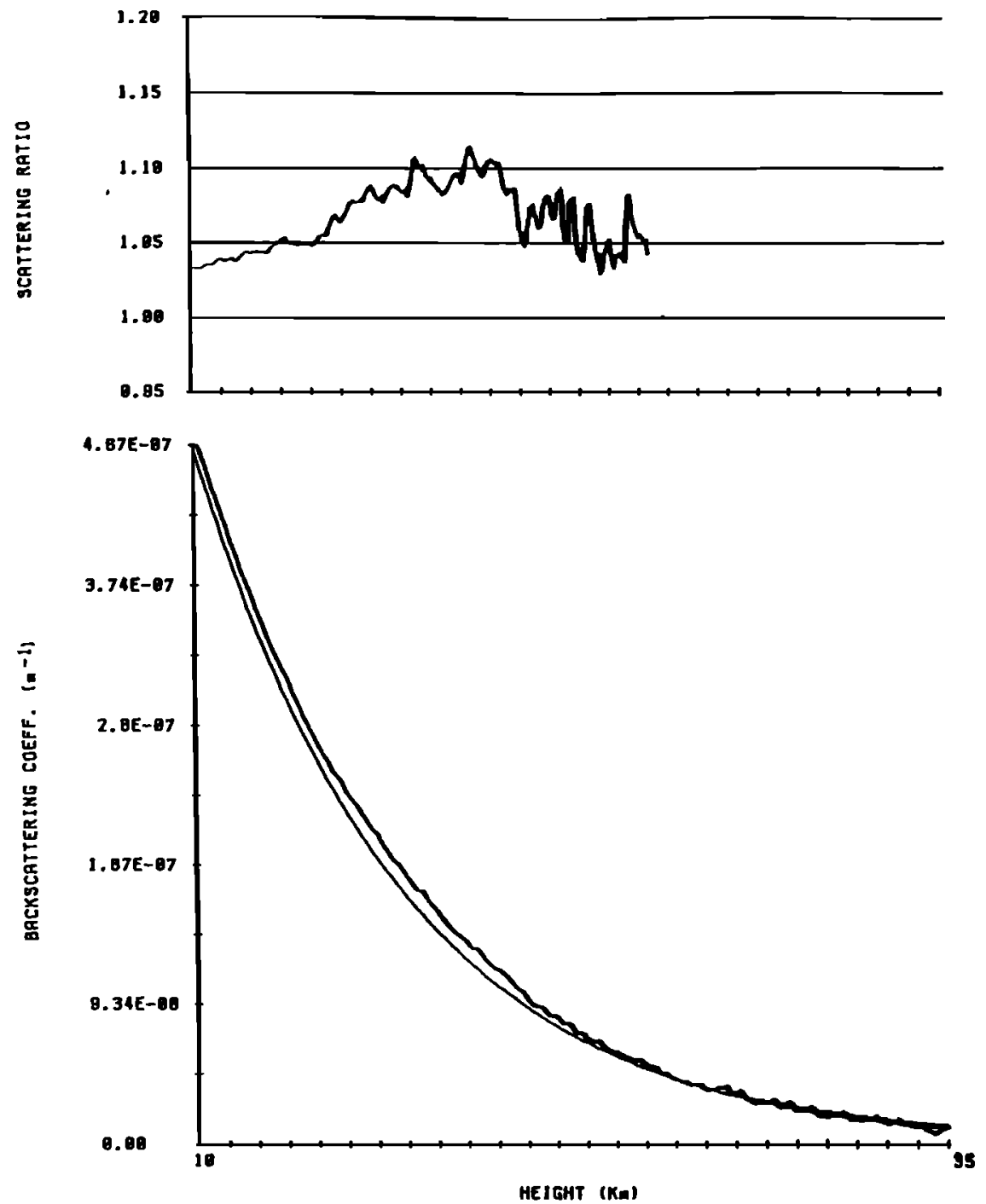

Fig. 1. Scattering ratio and backscattering coefficient altitude profiles as observed with the lidar system for background aerosol conditions. The integrated backscatter coefficient between 10 and $25 \mathrm{~km}$ is $1.5 \times 10^{-4}$.

backscattering structures, and 0.025 for background aerosols [McCormick and Swissler, 1989 ].

All through the year the ancillary temperature and density data were only available up to an average altitude of $15 \mathrm{~km}$ due to the launching technique of the radiosondes which could not prevent explosion of the balloon when exposed to very low temperatures in the lower stratosphere. From September on, a nęw method of operation was adopted which allowed the balloon to reach much higher altitudes. However, because of the lack of a complete temperature data set, the following ancillary data were used in the analysis:

1. For the summer period, the molecular backscattering profile was evaluated by averaging the number density profiles obtained from radiosoundings at Dumont d'Urville during three antarctic summers: 1987-1988, 1988-1989, and 1989-1990. It was used for a first data analysis up to the end of July, when the cooling of the stratosphere began.
2. For the winter period, an atmospheric density profile was derived from the SAM II data obtained during the last week of July 1989 [M.P. McCormick, private communication, 1989]. These data were used up to the end of September.

Assumptions on the molecular atmosphere have an effect on the retrieved value of the scattering ratio. In the case of background aerosols (see Figure 1) the bias on the scattering ratio is on the order 0.03 around $10 \mathrm{~km}$. Such a value can be neglected when compared to the higher values of the scattering ratio obtained in the case of PSC. Figure 2 shows a typical example of PSC signature as seen by lidar for the p-polarization, while Figures $3 a$ and $3 b$ show the related scattering ratios on the $p$ - and s-polarization planes, respectively.

In order to validate the lidar measurements, a comparison in terms of aerosol extinction profile was performed between the lidar and SAM II satelitite measurements. The results are shown on Figure 4, where two aeorols extinction profiles 


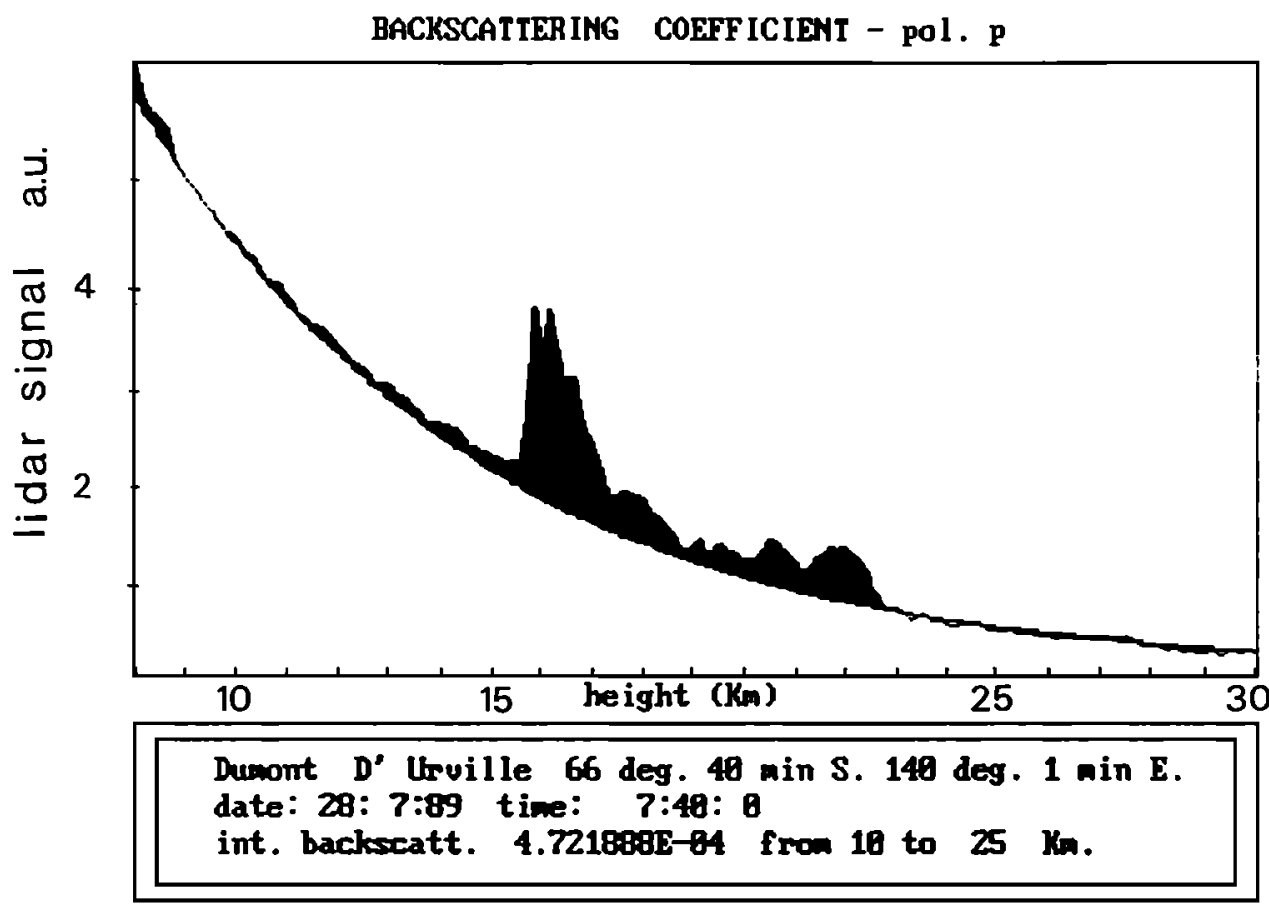

Fig. 2. Backscattering coefficient in the p-polarization plane as measured with the lidar system in the presence of polar stratospheric clouds.

are plotted as measured on February 8, 1988, when the lidar was still in Terra Nova Bay. For this comparison, the lidar data at $532 \mathrm{~nm}$ were converted into extinction data at $1000 \mathrm{~nm}$, the measurement wavelength of SAM II, using typical values of 0.025 for the backscatter to extinction ratio and 1 for the Angstrom coefficient [McCormick and Swissler, 1989]. This analysis shows that, even with relatively low aerosol loading, the lidar data and the SAM II data are in good agreement. This comparison has been carried out with the data obtained for the $p$ polarization plane only, as the signal obtained on the s-polarization plane in the case of background aerosol loading is substantially negligible.

\section{Depolarization Ratio}

Depolarization of the laser beam is induced by Rayleigh and Mie scattering and by reflection in the optical receiving system. Let $I_{\text {, and }} I_{2}$ be the range and transmission corrected lidar signals, received in the $p$ - and $s$-polarization planes, respectively:

$$
\begin{gathered}
I_{1}=G_{1} K_{0}\left[T_{p}(1-D)\left(\beta_{m p}+\beta_{a p}\right)\right] \\
I_{2}-G_{2} K_{0}\left[T_{p} D\left(\beta_{m p}+\beta_{a p}\right)+T_{s}\left(\beta_{m q}+\beta_{a s}\right)\right]
\end{gathered}
$$

where for each channel (i) $I_{0}$ is the laser power (emitted in the $p$-polarization plane), $G_{\text {i }}$ is the amplification factor of the electronic system including the photomultiplier tube, $K$ is the calibration factor common to the two channels, $T_{P}$ and $T_{s}$ are the transmission factors specific to the $\mathrm{p}$ - and $\mathrm{s}$-polarization planes, $\beta_{\mathrm{p}}, \beta_{\mathrm{s}}, \beta_{\mathrm{s}}$, and $\beta_{\text {ap }}$ are the molecular and aerosol backscattering coefficients for each polarization plane, and $D$ is the depolarization factor induced by the system. These formula are obtained assuming that the emitted laser beam is fully polarized and that the s-component induced on channel 1 by the receiving system is negligible compared to the p-component Induced on channel 2.

After correction of the system depolarization factor, the depolarization ratio can be defined in two different ways, depending on whether the depolarization induced by Rayleigh scattering is included or not. The most widely used definitions in lidar experiments express the depolarization ratio as a function of the lidar signals received on each of the two polarization channels. We define the depolarization ratio as

$$
\delta-\frac{\beta_{\mathrm{mB}}+\beta_{\mathrm{BB}}}{\beta_{\mathrm{mP}}+\beta_{\mathrm{aP}}+\beta_{\mathrm{mB}}+\beta_{\mathrm{AB}}}
$$

while in other experiments [Poole et al., 1990; Browell et al., 1990], the depolarization ratio is simply defined as the ratio of the components relative to each channel:

$\delta^{\prime}-\left(\beta_{\mathrm{as}}+\beta_{\mathrm{as}}\right) /\left(\beta_{\mathrm{pp}}+\beta_{\mathrm{ap}}\right)$.

The parameter $\delta$ is calculated from the signal received on each channel (equations (2) and (3)), provided calibration factors are known.

$$
\delta=\frac{I_{2} g(1-D)-I_{1} D}{I_{2} g(1-D)-I_{1}(1 / T-D)}
$$

where $g$ is the ratio $G_{1} / G_{2}$ and $T$ is the ratio $T_{p} / T_{s}$.

The ratio $g$ is measured by exchanging on a clear day, and on the shortest possible time interval, the electronic channels and photomultiplier tubes. $T$ has to be determined from the system's specifications, assuming that the system is correctly aligned so that the p- 


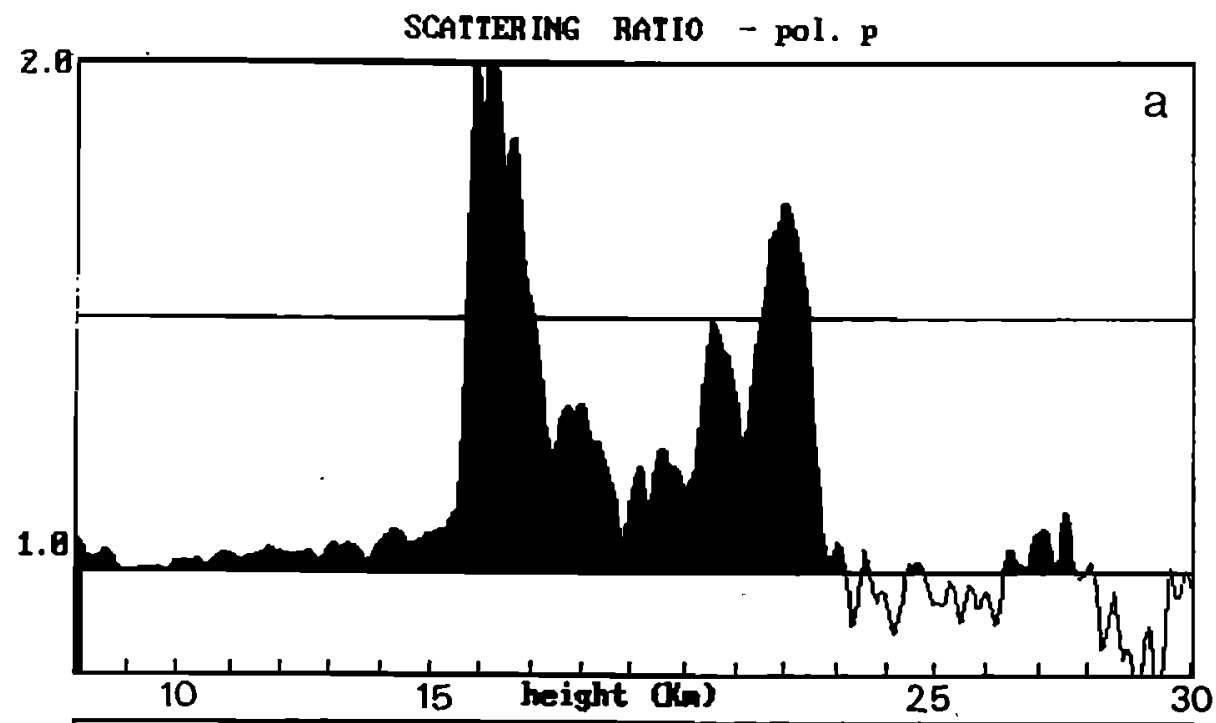

Dumont $D^{\prime}$ Uruille $66 \mathrm{deg} .40 \mathrm{~min}$ S. $140 \mathrm{deg} .1 \mathrm{~min} \mathrm{E}$. date: 28: 7:89 time: 7:49: 8 max scatt. ratio= 2.133034 at 16.2 hin.

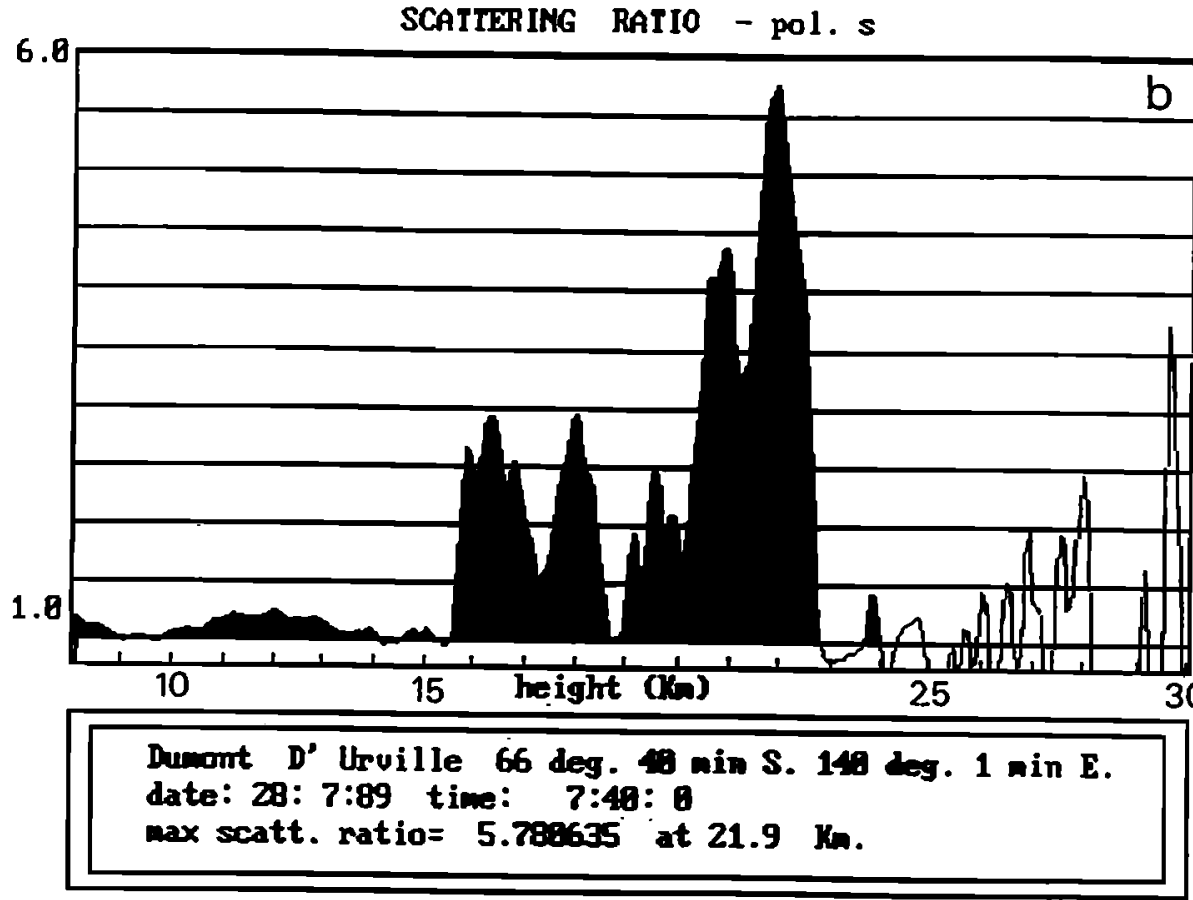

Fig. 3. Scattering ratio versus altitude in the (a) p-polarization and (b) spolarization planes for PSC observations as represented in Figure 2.

component of the electric field of the laser beam lies in the plane of incidence of the $45^{\circ}$ forward mirror used to direct the received signal into the polarizer and the photomultiplier tube. The sum of the system and the Rayleigh depolarization factors ( $D$ and $D_{m}$, respectively) can be estimated on a clear day $m$ in atmopheric regions where the aerosol scattering contribution is assumed to be negligible with respect to molecular scattering; for example, at altitude levels around $8 \mathrm{~km}$,

$$
\mathrm{D}+\mathrm{D}_{\mathrm{m}}=\frac{\mathrm{gI_{2 }} / \mathrm{I}_{1}}{1+\mathrm{gI} \mathrm{I}_{2} / \mathrm{I}_{1}}
$$

with $D_{m}$ defined as

$$
D_{m}=\frac{\beta_{m s}}{\beta_{m s}+\beta_{m p}}
$$

Throughout 1988, the system depolarization factor never exceeded a few percent $\left(D+D_{m}=\right.$ 


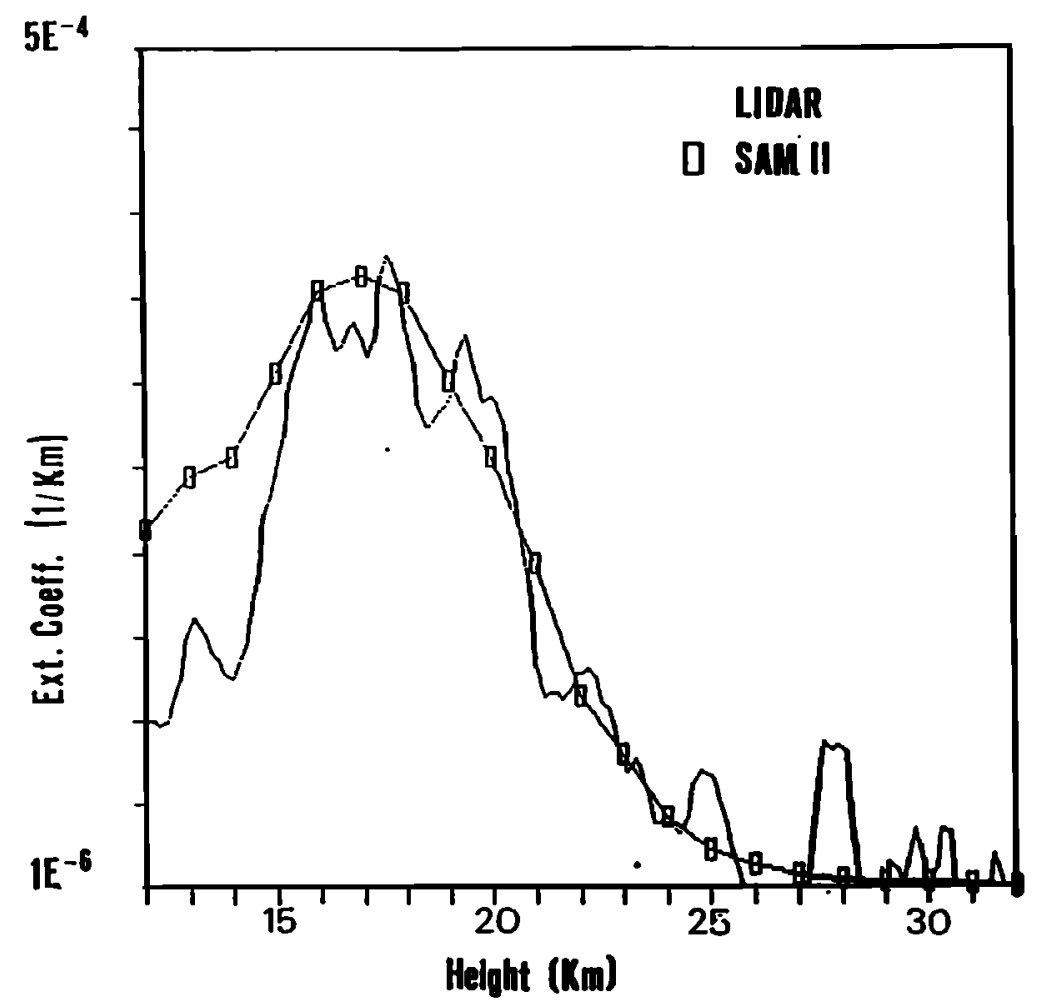

Fig. 4. Comparison between Mie extinction coefficients as measured with the lidar and the SAM II instrument.

3.68), while it reached values of about 78 during the 1989 winter. The increase of $D$ during this period was in fact due to a degradation of the alignment of the laser transmitter after a strong catabatic wind event in early March 1989.

In order to perform comparisons with theoretical models based on the Mie scattering theory, it is preferable to use another definition of the depolarization ratio which does not take into account the Rayleigh component:

$$
\delta_{.}-\frac{\beta_{\mathrm{as}}}{\beta_{\mathrm{as}}+\beta_{\mathrm{ap}}}
$$

Here, $\delta$ is deduced from $\delta$ by the following relationship:

$$
\delta_{0}-\frac{\delta R-D_{m}}{R-1}
$$

where $R$ is the total backscattering ratio related to the sum of the $s$ - and p-components. $R$ is obtained from the backscattering ratio $R_{1}$ calculated from the signal received on channel 1 by

$$
R-R_{1} \frac{1-D_{m}}{1-\delta}
$$

\section{Operational Mode}

The system was operated twice a week until the end of April for stratospheric measurements. The frequency of these measurements was then increased throughout the winter and spring period in order to provide an appropriate data base on polar stratospheric clouds. Table 1 shows the histogram of the measurements performed throughout the year. From mid-February to the end of March, technical problems prevented stratospheric measurements. In September 1989, the sky was usually overcast, and only few measurements could be performed.

Typically during the polar night, averaging was performed over 500 shots (2.5 min.), while 2000 shots (10 min.) were necessary during daytime conditions. From the beginning of June on, stratospheric lidar measurements were performed daily, when meteorological conditions were favorable. On some occasions, typically once per week when PSC were present, a long sequence of measurements was carried out, with an average profile every 10-15 min. and messurements lasting up to 10 hours. The corresponding dates are marked by an asterisk in Table 1 . This was done in order to follow the PSC evolution and to monitor possible vertical motions. Polar stratospheric clouds were detected from June until the second part of September 1989. A first analysis of the observations is reported hereafter.

\section{Experimental Results: Discussion}

The signatures of three types of scattering layers can be observed on the lidar data in the altitude range from 8 to $25 \mathrm{~km}$ : background aerosols between 10 and $25 \mathrm{~km}$, cirrus clouds at lower altitudes, and polar stratrospheric clouds which are expected to be forned over the whole altitude range between 10 and $25 \mathrm{~km}$. In the absence of clouds, the signature of the aerosols is clearly seen. It corresponds to an integrated backscatter coefficient between 12 and $25 \mathrm{~km}$ of the order of $1.5 \times 10^{-4}$ and a maximum value of 
TABLE 1. Days of PSC Measurements, 1989

\begin{tabular}{|c|c|c|c|c|c|c|c|c|c|c|c|}
\hline Jan. & Feb. & March & April & May & June & July & Aug. & Sept. & Oct. & Nov. & Dec. \\
\hline & & & & & $\begin{array}{l}1 \\
2\end{array}$ & & & & & & \\
\hline 7 & & & & & 3 & 7 & & & & & \\
\hline 9 & & & & & 4 & 8 & $2^{*}$ & & & & \\
\hline 10 & & & & & $5^{\star}$ & 9 & 3 & & & & \\
\hline 11 & & & & & $6^{*}$ & 11 & 7 & & 3 & & \\
\hline 13 & & & & & 7 & $16^{*}$ & 15 & 2 & 7 & & \\
\hline 14 & & & & 3 & 8 & 17 & $18^{*}$ & 6 & 9 & & \\
\hline 16 & & & 11 & 7 & 10 & $18^{*}$ & $19^{*}$ & 13 & 10 & 12 & \\
\hline 17 & & & 12 & 9 & 11 & 19 & 20 & $15^{*}$ & 14 & 15 & \\
\hline 18 & & & 21 & $15^{*}$ & 12 & $23^{*}$ & $22^{*}$ & 16 & 16 & 18 & \\
\hline 19 & 1 & & 22 & $16^{*}$ & $13^{*}$ & $24^{\prime \prime}$ & 26 & 19 & 19 & 20 & \\
\hline 20 & 5 & & 24 & 18 & 14 & 25 & 27 & $20^{*}$ & 20 & 21 & \\
\hline 22 & 6 & 3 & 26 & 19 & 18 & $26^{*}$ & $28^{\star}$ & 27 & 23 & 28 & \\
\hline 25 & 17 & 4 & $28^{*}$ & 28 & 19 & $27^{*}$ & 29 & 28 & 24 & 29 & \\
\hline 26 & 23 & 28 & $30^{*}$ & 29 & 23 & $28^{*}$ & $30^{*}$ & 30 & 25 & 30 & 1 \\
\hline
\end{tabular}

the scattering ratio $R$ of 1.1 at a peak altitude of $17 \pm 1 \mathrm{~km}$. Such values have been observed throughout the year and are representative of background aerosol content in the lower stratosphere.

Cirrus clouds are generally observed in the range from 6 to $12 \mathrm{~km}$ in relation to varlations in the tropopause height. They correspond to higher values of the scattering ratio, generally above 2 , and depolarization ratios above 308 . These signatures are similar to the one expected from some types of polar stratospheric clouds, which potentially leads to difficulties in the data interpretation, especially at lower altitudes, where both type of clouds could be present. Two criteria can be used to distinguish between cirrus clouds and PSC. The first one relates to the temperature observed at the altitude of the cloud, as PSC will only be observed if the temperature drops below $195 \mathrm{~K}$ (type I) or $187 \mathrm{~K}$ (type II), for average values of water vapor and nitric acid partial pressure. The second criterion is based on lidar observations of the depolarization ratio. Type I PSC are made of relatively small particles $(\approx 1$ $\mu m)$ of nitric acid trihydrate [Toon et al., 1986]. Toon [1990] introduces a further distinction of type I PSC by considering the shape and size of the particles, the ratio between the numbers of cloud particles, and condensation nuclei per unit volume. These characteristics, as summarized in Table 2, lead to different values of the depolarization and scattering ratios for type Ia and type Ib PSC and are potentlally detectable from lidar signatures [Browell et al., 1990].

Type II PSC are water ice clouds with particle sizes in the $2 \mu \mathrm{m}$ to $10 \mu \mathrm{m}$ range. This leads to larger values of the depolarization ratios ranging from 20z to 508 [Toon et al., 1990]. Such values, which might also indicate the presence of nonspherical paticles, are similar to the one expected from ice crystals in cirrus clouds.

Consideration of the altitude dependence of the three variables, i.e., temperature (from radiosonde data, if available, or meteorological charts from satellite data), backscatter coefficients, and depolarization ratios from lidar sounding, might then allow us to distinguish between cirrus clouds and PSC, and between the various types of PSC. The temperature varlations in the troposphere and lower stratosphere, as determined from the radiosonde date obtained over Dumont d'Urville throughout the year 1989, are represented in Figure 5.

Examples of simultaneous detection of cirrus clouds and PSC are given in Figure 6, which corresponds to measurements taken on August 3 , 1989. A cirrus cloud is observed between 7 and $10.5 \mathrm{~km}$ with a baskscattering ratio of 6 and large depolarization ratios between $35 z$ and 408 . Two stratospheric clouds are also detected at higher altitudes between 18 and $20.5 \mathrm{~km}$ and 23 and $25 \mathrm{~km}$, respectively. In this particular case the altitude location of the clouds is sufficient for data interpretation. This is confirmed by the temperature measurements which indicate temperature in the range $230 \mathrm{~K}$ to $205 \mathrm{~K}$ between 7

TABLE 2. Characteristics of Type I Polar Stratospheric Cloud [from Toon, 1990]

\begin{tabular}{lcc}
\hline & Type Ia & Type Ib \\
\hline Particle shape & aspherical & spherical \\
Particle size & $>1 \mu \mathrm{m}$ & $0.5 \mu \mathrm{m}$ \\
Cloud particles/CN & $<1$ & 1 \\
Depolarization ratio & $>108$ & $<108$ \\
Backscatter ratio & $<2$ & $>2$ \\
\hline
\end{tabular}




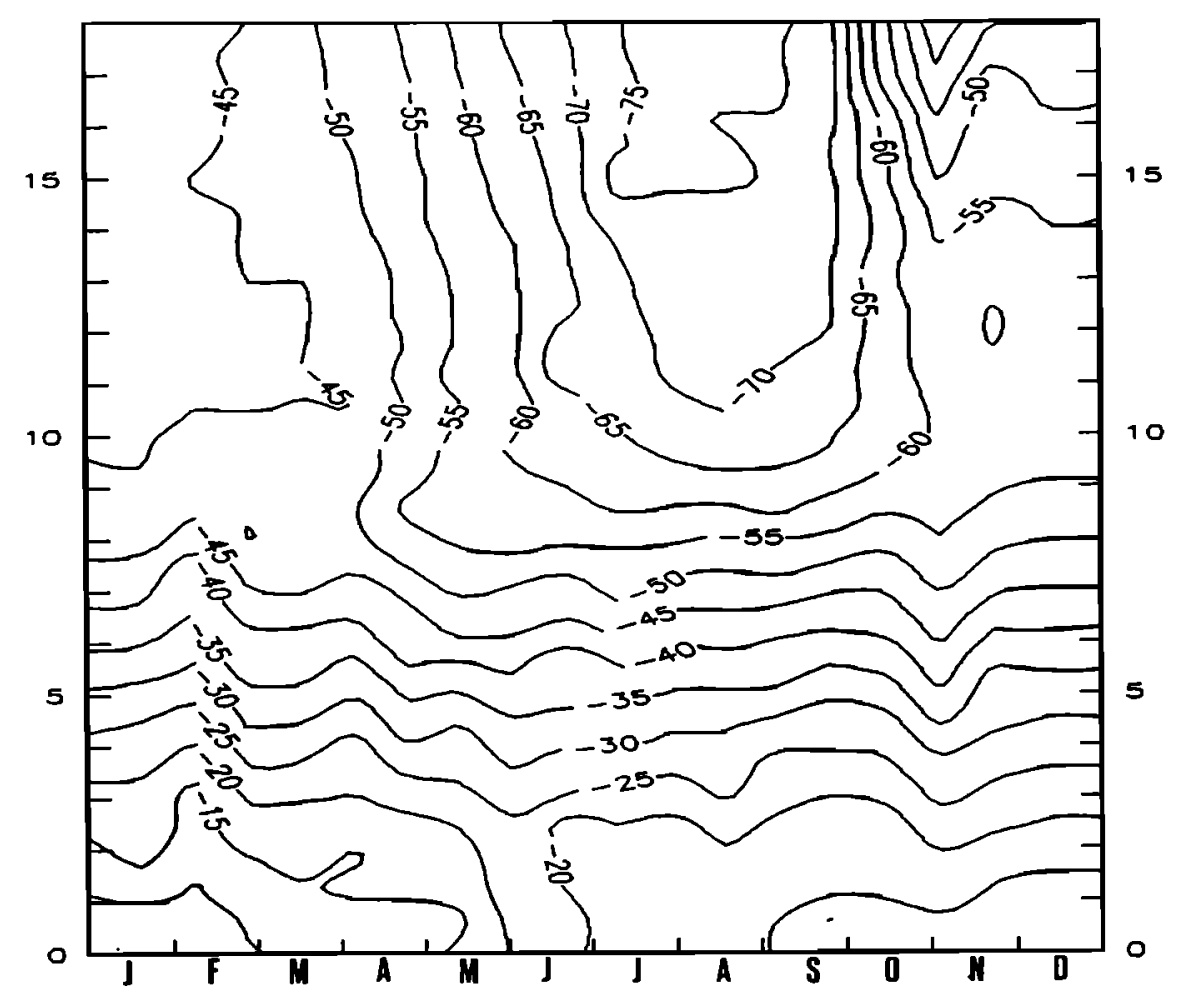

Fig. 5. Temperature field cross section as measured by radiosondes over Dumont d'Urville during the year 1989 .

and $10.5 \mathrm{~km}$, well above the temperature threshold for PSC formation, taking into account typical water vapor mixing ratios observed in the arctic stratosphere [Murphy et al., 1990]. Although temperature measurements are not available above $19 \mathrm{~km}$ on this particular day, the observed temperature between 17 and $19 \mathrm{~km}$ has dropped below $196 \mathrm{~K}$, reaching a lower value of $191.2 \mathrm{~K}$, compatible with the formation of type I PSC.

Consideration of the depolarization ratios might then give further indication of the nature of the two observed PSC (Figure 7). The lower PSC cloud corresponds to a backscatter ratio of 3.5 and very low depolarization ratio, characteristic

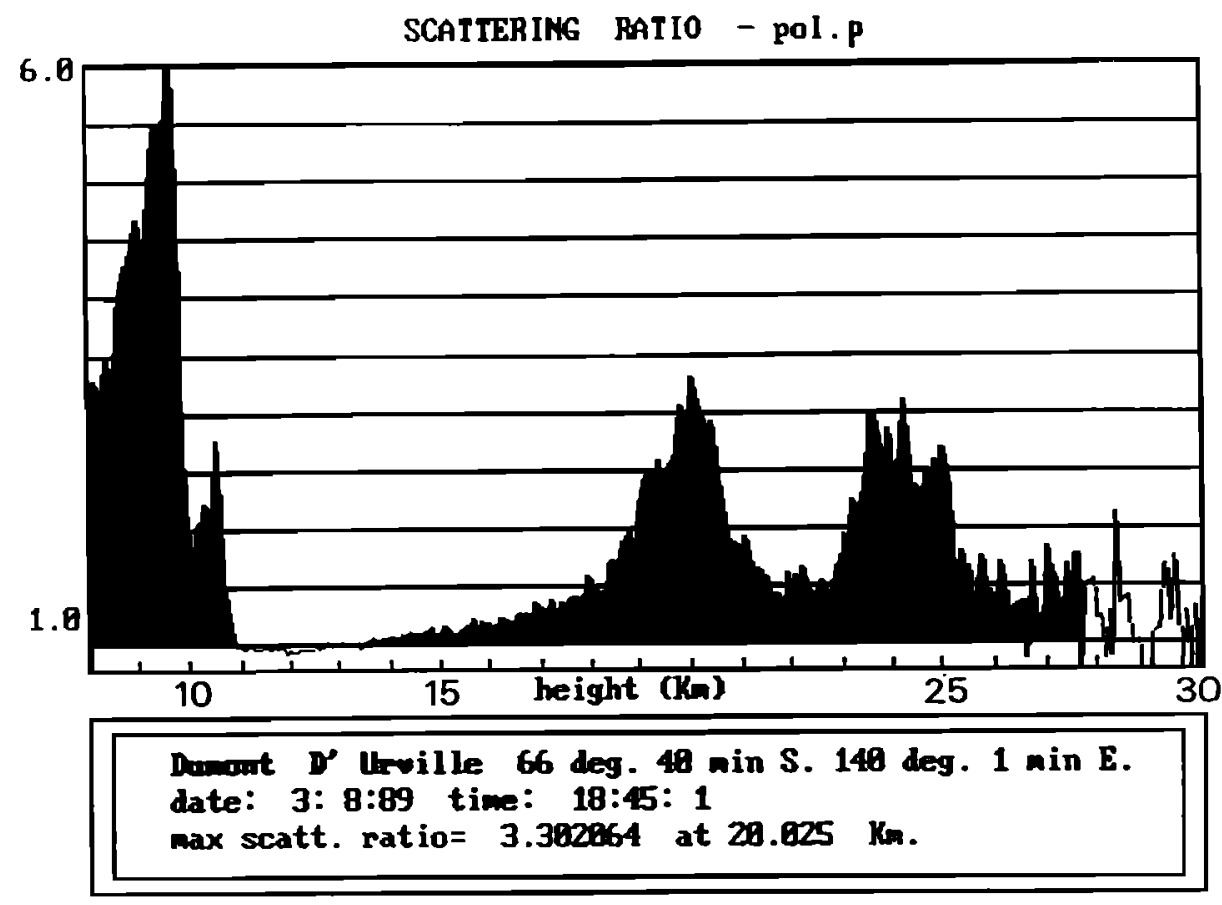

Fig. 6. Example of the simultaneous measurement of cirrus clouds and PSC. 


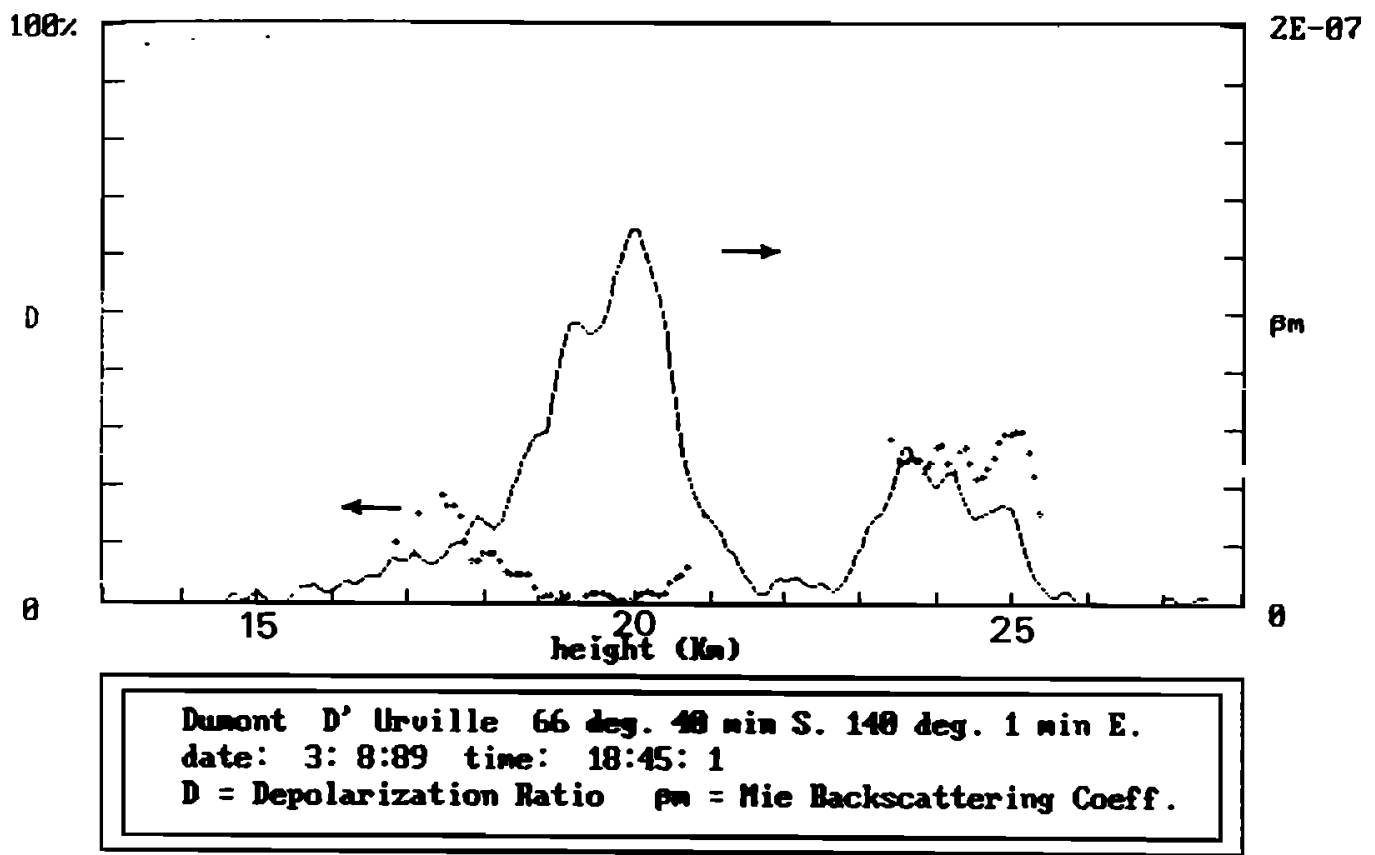

Fig. 7. Depolarization ratio (dotted line) and Mie backscattering coefficient (solid J.ine) versus altitude as measured on August 3, 1989.

of type Ib PSC following the classification of Toon [1990]. Although the presence of cirrus clouds at lower altitude results in a decrease of the signal to noise ratio at the upper level, due to the extinction of the laser enitted light, one can observe from Figure 7 a larger value of the depolarization ratio at the altitude of the uppermost cloud, indicating the presence of a type II PSC as confirmed by a scattering ratio of 3 (Figure 6). Such an interpretation of the data can be reinforced fron the temporal evolution of this cloud (Figure 8) as a strong vertical motion is observed, leading to a lowering of the layer of over 1 ka in a 2-hour period of time. If sedimentation is the primary process responsible for this evolution, the downward velocity is in the $15 \mathrm{~cm} \mathrm{~s}^{-1}$ range and thus only compatible with sedimentation of larger particles.

According to the above-mentioned criteria, polar stratospheric clouds were detected over

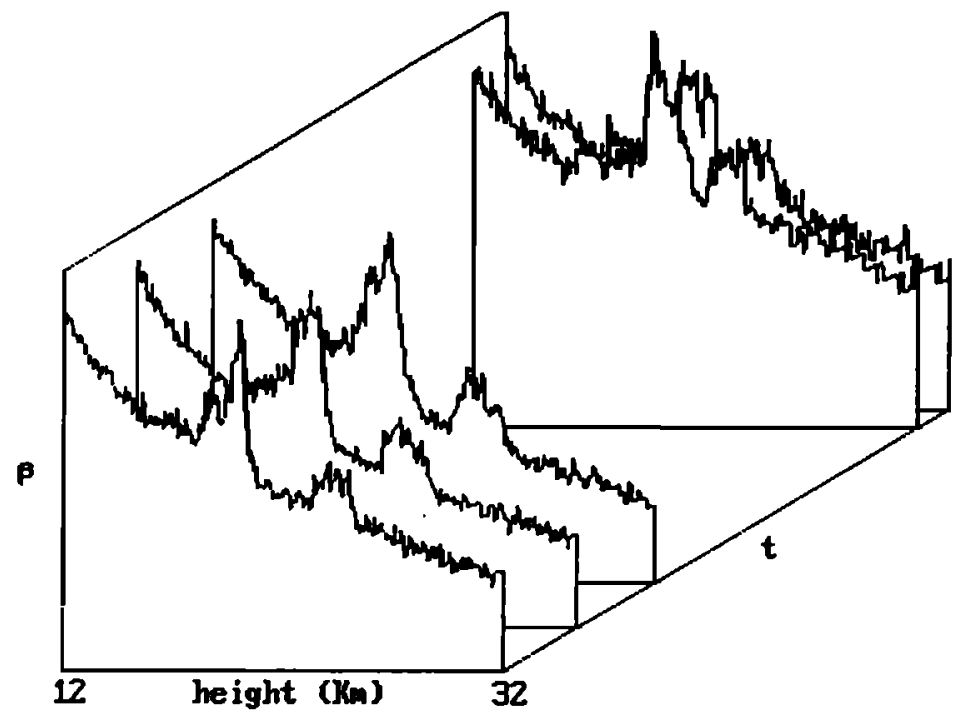

BACKSCAT IERING IDMPORAL EUOWTION

Dumont d' Irville $66^{\circ}$. $40^{\prime}$ S $140^{\circ}$. 1' E date 3:8:89 time from 17h:44n to $20 \mathrm{~h}: 45 \mathrm{~m}$

Fig. 8. Temporal evolution of PSC layers as observed from 1744 to 2045 LT on August 3 , 1989 . 


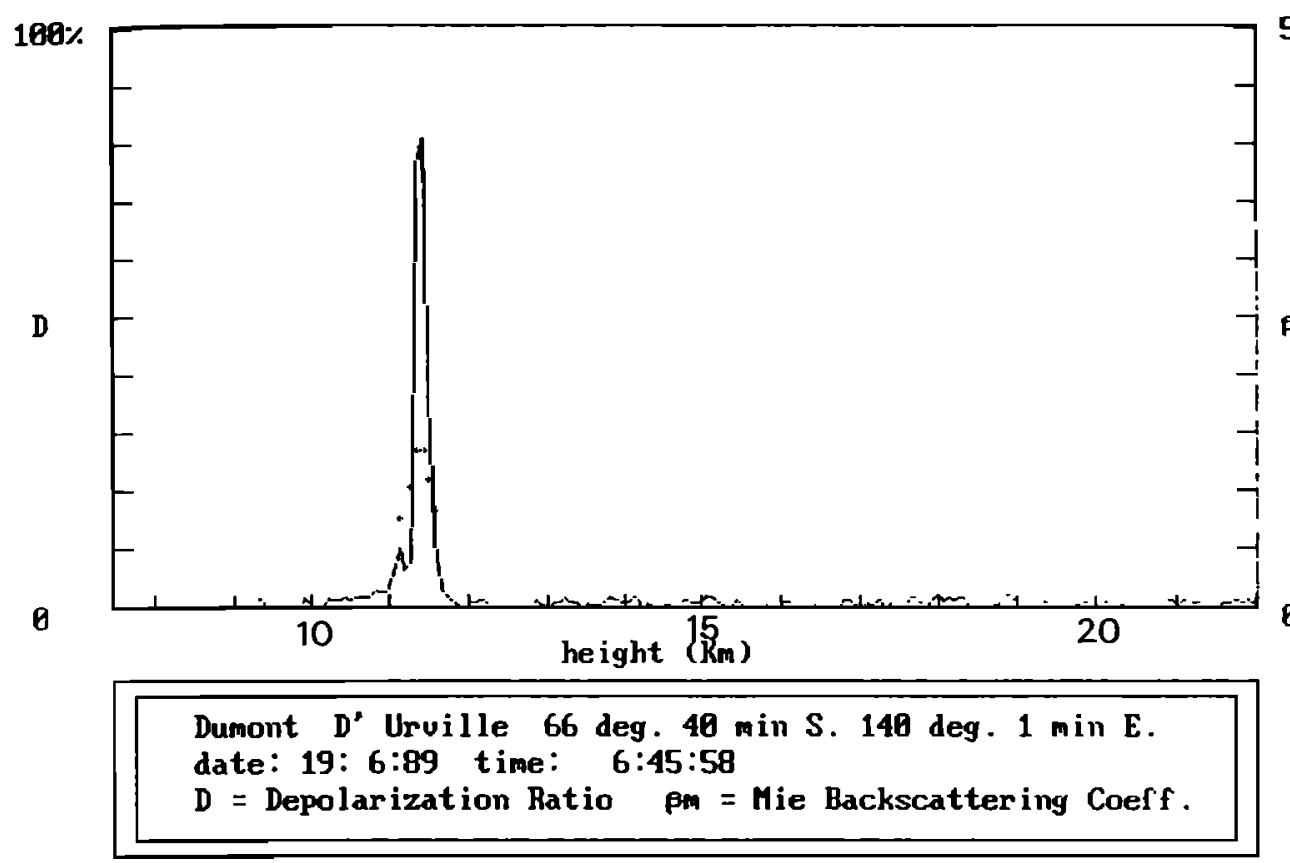

Fig. 9. Depolarization ratio and Mie backscattering coefficient as measured on June $19,1989$.

Dumont d'Urville starting in late June 1989. The first detection occurred on June 19 and was followed by PSC observations on July 27 and 28 . August 2, 3, 18, 19, 28, 29, and 30 , and September $2,9,15,16$, and 19. No PSC were clearly detected after this latter date. The observations performed on June 19 give an example of the interest of depolarization measurements for the identification of PSC (Figure 9). On this particular day, the tropopause height was observed at $10.8 \mathrm{~km}$ with a temperature value of $196 \mathrm{~K}$. The measured depolarization ratio of $25 \%$ is likely to be compatible with the presence of a type Ia PSC, as the scattering ratio does not exceed 2.2 .

On July 27 and 28 the temporal evolution of the PSC has been recorded over an extended period of time (Figure 10a). Several PSC are observed between 15 and $23 \mathrm{~km}$ in a layered structure with scattering ratios as high as 3 . The corresponding

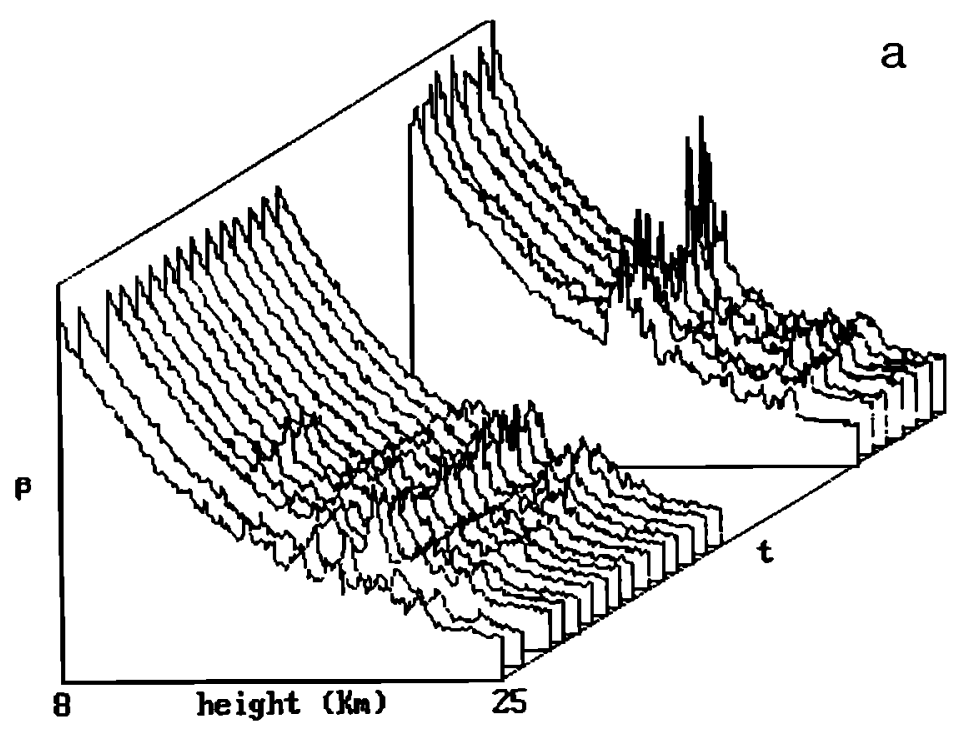

BACKSCATTERING TETPORAL EVOLUTION

Dumont $d^{\prime}$ Uruille $66^{\circ}$. $49^{\circ}$ S $140^{\circ}$. 1' E date $27: 7: 89$ time from $21 \mathrm{~h}: 23 \mathrm{~m}$ to $7 \mathrm{~h}: 4 \mathrm{Bm}$

Fig. 10a. Temporal evolution of the backscattering coefficient as observed on July 27 and 28,1989 , in the presence of layered PSCs. 


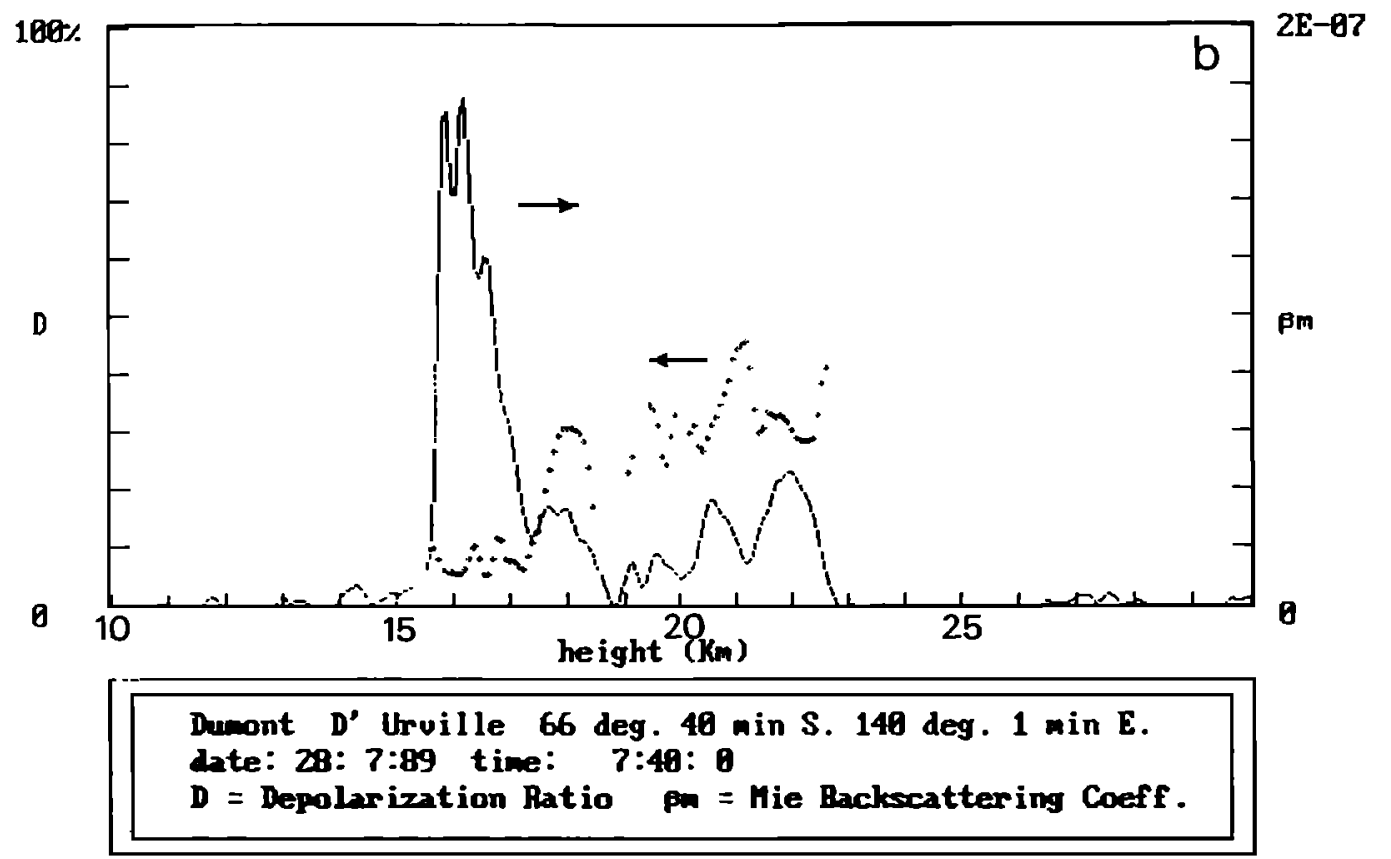

Fig. 10b. Depolarization ratio and Me backscattering coefficient versus altitude for the same time period.

depolarization ratio ranges between 108 and 408 (Figure 10b), indicating the presence of rather large particles. Temperature charts obtained from the European Centre for Medium-Range Weather Forecasts, indicate a minimum temperature value of $193 \mathrm{~K}$ up to $25 \mathrm{~km}$. As for the case of August 3 , a descending motion is observed in the various layers which corresponds to a downward motion of $4 \mathrm{~cm} \mathrm{~s} \mathrm{~s}^{-1}$. According to Toon et al. [1989], such velocities are characteristic of nonspherical large particles with equivalent radius in the 5 $\mu \mathrm{m}$ to $10 \mu \mathrm{m}$ range, typical of type II or type Ia PSC. Consideration of the temperature values (above $190 \mathrm{~K}$ ), depolarization ratios (above $10 \%$ and reaching 308 at the uppermost levels), and scattering ratios (from 1.2 to 2; Figure 10c) might indicate for the presence of a type Ia PSC.

During the second part of August and September, PSC were observed at lower altitudes between 12 and $17 \mathrm{~km}$. Figures $11 \mathrm{a}$ and $11 \mathrm{~b}$ represent the scattering ratio for the p-polarization and the depolarization ratio, respectively, according to

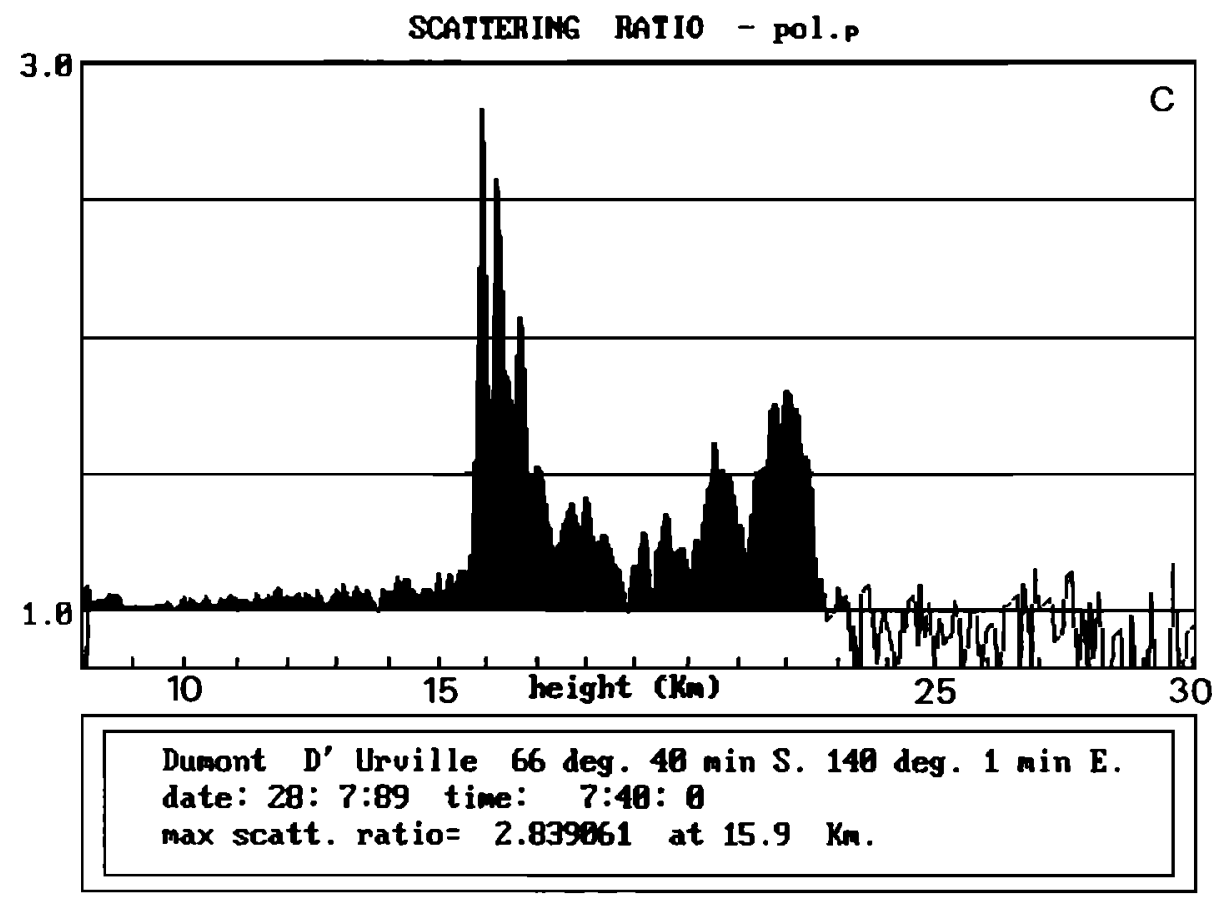

Fig. 10c. Scattering ratio in the p-polarization plane. 


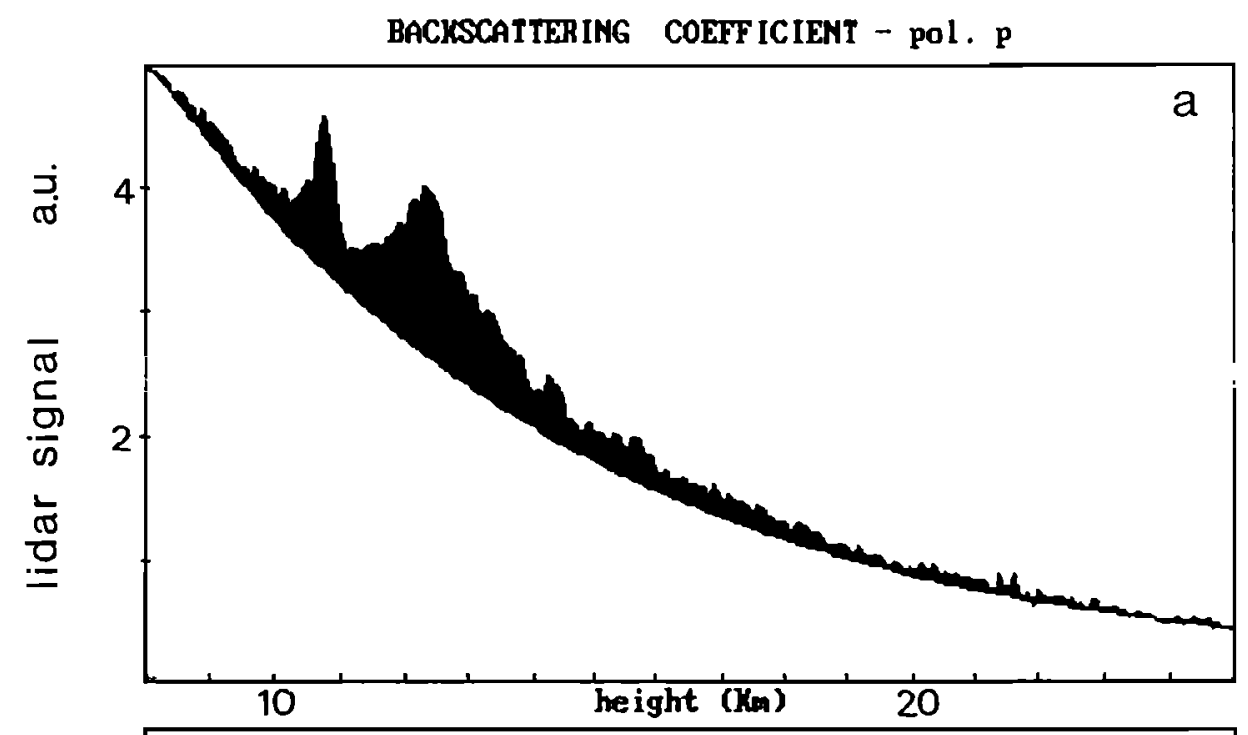

Dusout $D^{\prime}$ Uruille $66 \mathrm{deg} .40 \mathrm{~min} S .140 \mathrm{deg} .1 \mathrm{~min} E$. date: $30: 8: 89$ time: 17:21:58

int. backscatt. $4.889144 \mathrm{~L}-84$ from 18 to $25 \mathrm{~km}$.

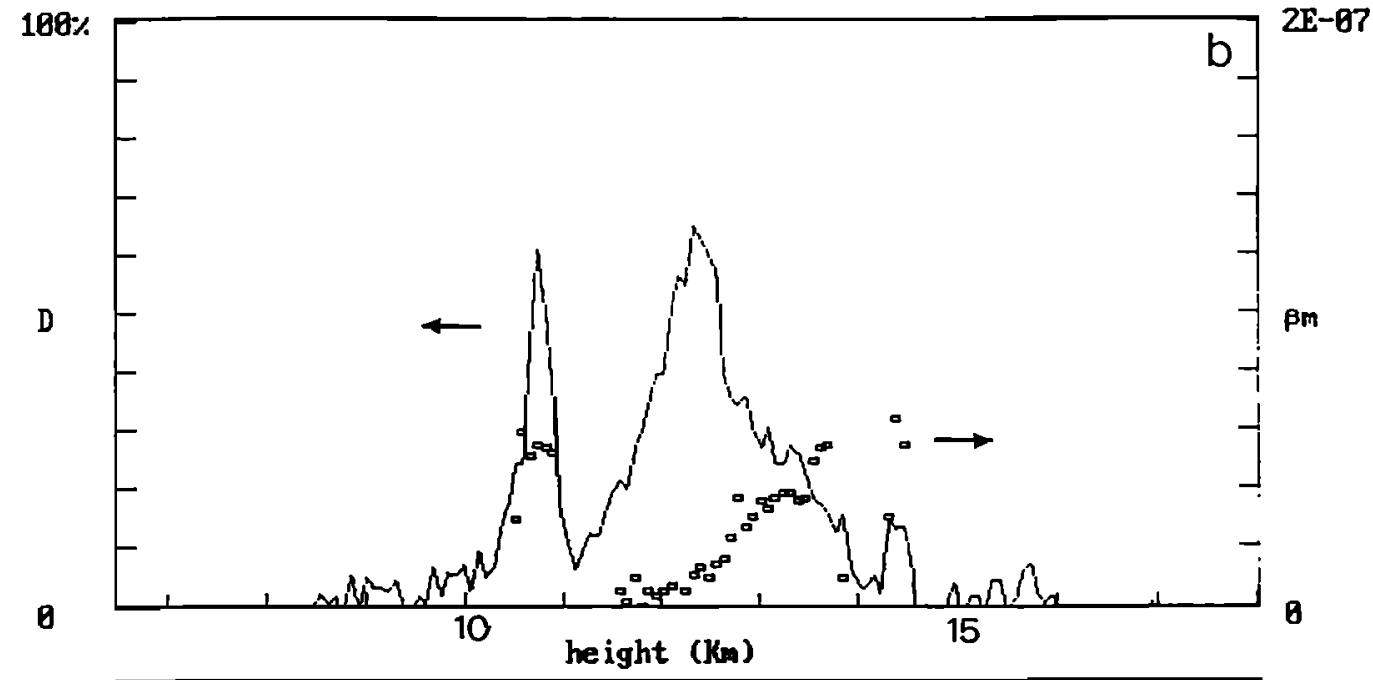

Duromt $D^{\prime}$ Urville 66 deg. 49 min S. 140 deg. 1 min E. date: 39: 8:89 time: 17:21:58

D = Depolarization Ratio $\mathrm{mm}=$ Mie Backscattering Coeff .

Fig. 11. (a) Backscattering coefficient in the p-polarization plane versus altitude as measured on August 30, 1989. (b) Depolarization ratio versus altitude.

equation (9), for August 30. The tropopause leve1 on that day was $12 \mathrm{~km}$ with temperatures of the order of $195 \mathrm{~K}$. Here again the simultaneous presence of a thin cirrus at $11 \mathrm{~km}$, and a PSC layer, just above, was observed. The cirrus presents a depolarization ratio of the order of 258, while for the PSC, two layers can be distinguished. The lower layer presents a very low depolarization ratio ( $\leq 58$ ) with a scattering ratio of 1.5 at $12.3 \mathrm{~km}$, and the higher layer a somewhat lower scattering ratio of 1.25 , with a much higher depolarization ratio, of the order of
208. This seems to show evidence for PSC of type Ib at the cloud base and of type Ia at the cloud top.

The increased presence of cirrus clouds during this time period substantially prevented observation of PSC, although type I PSC were still detected on September 19 between 16 and 17 km, which could be classified as type Ib PSC according to criteria indicated above (Figures $12 a$ and $12 b$ ). One may notice, from Figure 12a, the very large extension of the cirrus cloud from 9 to $13 \mathrm{~km}$, which in the absence of 


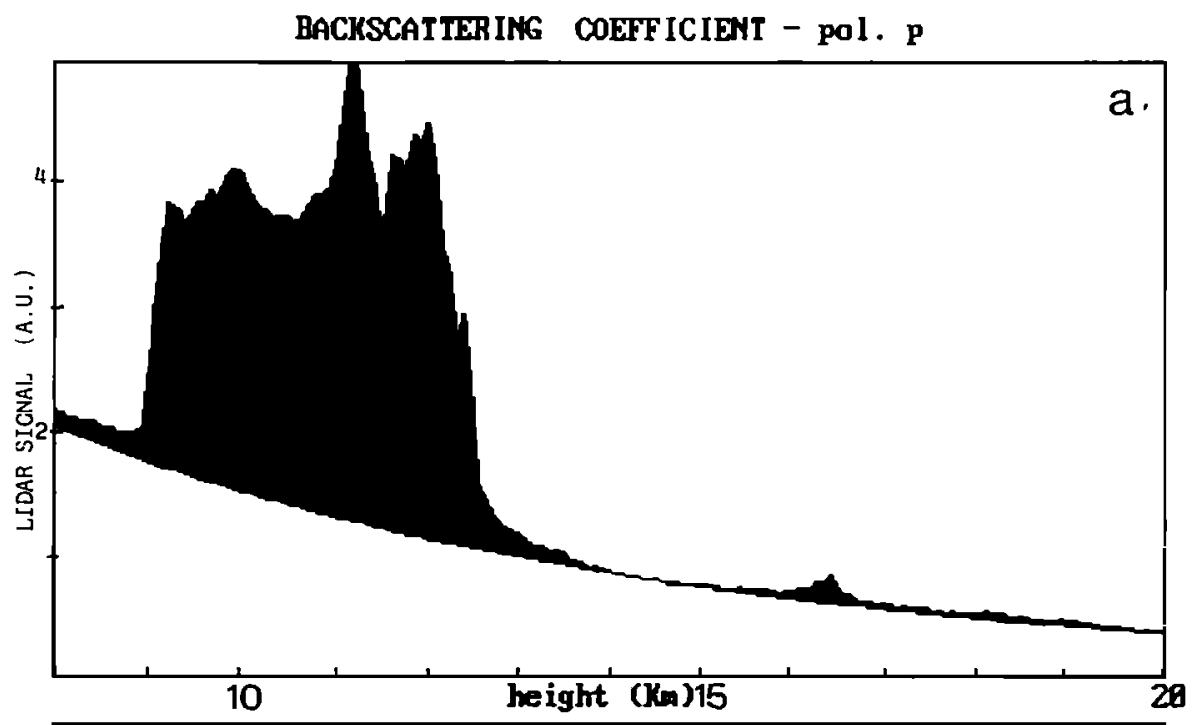

Dumont D' Urville $66 \mathrm{deg} .49$ min S. $149 \mathrm{deg} .1$ min E. date: 19: 9:89 time: 1: 5:31

int. backscatt. 6.193969E-85 from 14 to $29 \mathrm{~km}$.

108\%

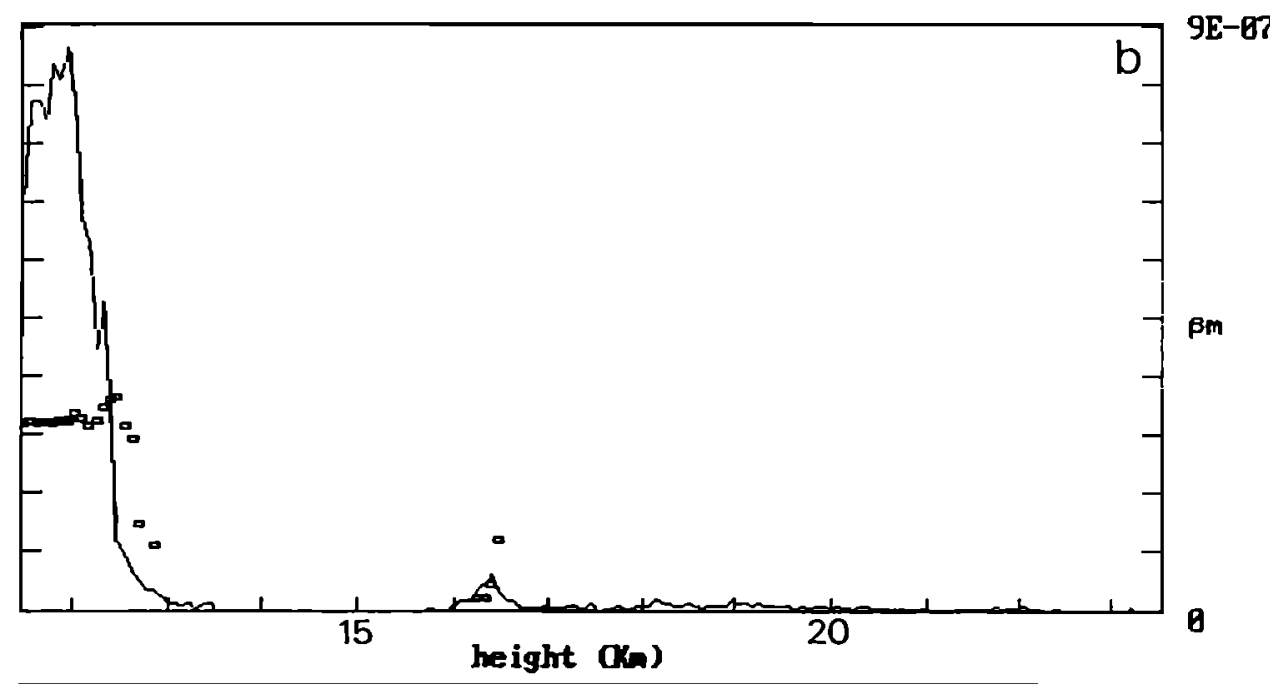

Dunomt $D^{\prime}$ Uruille 66 deg. 40 min S. 148 deg. 1 min E. date: 19: 9:89 tine: 1: 5:31

D = Depolarization Ratio $\mathrm{pm}=$ Mie Backscattering Coeff.

Fig. 12. (a) Backscattering coefficient in the p-polarization plane versus altitude as measured on September 19, 1989. (b) Depolarization ratio versus altitude.

depolarization and temperature data, could lead to misinterpretations. At the cloud base, the temperature on that day was of the order of 220 $\mathrm{K}$, and only above $13 \mathrm{~km}$ the stratosphere was cold enough ( $\leq 195 \mathrm{~K}$ ) for PSC formation. As already mentioned, no PSC were further detected after this date.

\section{Conclusion}

Lidar measurements performed throughout the year 1989 at the French Antarctic base in Dumont d'Urville, in the frame of the joint Italian-
French POLE experiment, have confirmed the ability of such active techniques to monitor with a high temporal and vertical resolution the vertical distribution of polar stratospheric clouds. The use of two polarization channels allows us to distinguish between various types of clouds and provided further development of the inversion techniques accounting for the expected relationship between particle sizes and depolarization effects [Flesia, 1991]. The further implementation of a DIAL lidar to simultaneously provide the vertical distribution of ozone in the troposphere and stratosphere [Pelon and Mégle, 
1982; Godin et al., 1989], presently planned for December 1990, will complement this monitoring activity.

Acknowledements. The authors wish to thank the entire French team at Dumont d'Urville, who made it possible for this experinent to be successful. A special thanks to Enxico Palchetti and Lionello Zuccagnoli of IROE-CNR, who brought, assembled, and tested the system in Dunont d'Urville. This work has been supported by the Italian PNRA and the French TAAF and Expeditions Polaires.

\section{References}

Browe11, E.V., C.F. Butler, S. Ismail, P.A. Robinette, A.F. Carter, N.S. Higdon, O.B. Toon, M.R. Shoeberl, and A.F. Tuck, Airborne lidar observations in the wintertime arctic stratosphere: Polar stratospheric clouds, Geophys. Res. Lett., 17(4), 385, 1990.

Flesia, C., A stochastic method for lidar inversion equation-Application for cloud size distribution measurements, Proceedings of the 2nd Italian National Workshop on the Antarctic Atmosphere, Italian Physical Society, in press, 1991.

Godin, S., G. Mégie, and J. Pelon, Systematic lidar measurement of the stratospheric ozone vertical distribution, Geophys. Res. Lett., $16(6), 547,1989$.

McCormick, M.P., and T.J. Swissler, Atmospheric effects, in Global Volcanism 1975-85, chap. 19, pp. 604-605, edited by L. Mc Clelland, Smithsonian Institution, Washington D.C., 1989. Murphy, D.M., K.K. Kelly, A.F. Tuck, and M.H. Proffitt, Ice saturation at the tropopause observed from the ER-2 aircraft, Geophys. Res. Lett. , 17(4), 353, 1990.

Pelon, J., and G. Mégie, Ozone monitoring in the troposphere and lower stratosphere: Evaluation and operation of a ground-based lidar station, J. Geophys. Res., 87(C7), 4947, 1982.
Poole, L.R., G.S. Kent, M.P. MeCormick, W.H. Hunt, M.T. Osborn, S. Schaffner, and M.C. Pitts, Dual-polarization alrborne lidar observations of polar stratospheric cloud evolution, Geophys. Res. Lett., vol. 17(4), $389,1990$.

Sacco, V.M. F. Castagnoli, M. Morandi, and L. Stefanutti, Elastic baskscattering lidar system for atmospheric measurements in Antarctica, Opt. and Quantum Electron., 21, 215, 1989.

Toon, O.B., Polar stratospheric clouds, paper presented at the International Workshop on Stratospheric Aerosol: Measurements, Properties, Effects, NASA-ARC, Moffett Field, Calif., March 27-30, 1990.

Toon, O.B., P. Hamill, R.P. Turco, and J. Pinto, Condensation of $\mathrm{HNO}^{3}$ and $\mathrm{HCl}$ in the winter polar stratosphere, Geophys. Res. Lett., 13, $1284,1986$.

Toon, O.B., R.P. Turco, J. Jordan, J. Goodman, and G. Ferry, Physical processes in polar strato-spheric clouds, J. Geophys. Res., 94(D9), 11, 359, 1989.

Toon, O.B., E.v. Browell, S. Kinne, and J. Jordan, An analysis of lidar observations of polar stratospheric clouds, Geophys. Res. Lett. , 17(4), 393, 1990.

J. Brechet and J. Piquard, Expeditions Polaires Françaises, 47 Avenue du Maréchal Fayolle, 75116, Paris, France.

M. Del Guasta, M. Morandi, and L. Stefanutti, IROE-CNR, Via Panciatichi 64, 50127 Firenze, Italy.

S. Godin and G. Mégie, Service d'Aéronomie du Centre National de la Recherche Scientifique, Université Pierre et Marie Curie, 4 Place Jussieu, 75231, Paris Cedex 05, France.

(Received August 14, 1990; revised March 13, 1991; accepted March 13, 1991.) 